\title{
Avaliação dos Níveis de Peroxidação Lipídica em Células da Mucosa Cólica após Aplicação de Enemas com Peróxido de Hidrogênio. Estudo Experimental em Ratos
}

\author{
Evaluation of Lipid Peroxidation Levels on Mucosa Colonic Cells Afther \\ Application of Hydrogen Peroxide in Enemas. \\ Experimental Study in Rats
}

\author{
LETÍCIAHELENA SOUSA MARQUES ${ }^{1}$, CAMILAMORAIS GONÇALVES DA SILVA ${ }^{2}$, THAIS MIGUELDO MONTE \\ LAMEIRO ${ }^{3}$, MARCOS GONÇALVES DEALMEIDA $^{3}$, FERNANDO LORENZETTIDACUNHA ${ }^{3}$, JOSÉAIRES PEREIRA $^{4}$, \\ CARLOS AUGUSTO REAL MARTINEZ ${ }^{5}$
}

\begin{abstract}
1. Acadêmica do Curso de Medicina da Universidade São Francisco, Bragança Paulista, São Paulo. Bolsista do Programa Institucional de Bolsas de Iniciação Científica (PIBIC/CNPq); ${ }^{2}$ Pós-Graduanda. (Mestrado) do Programa de Pós-Graduação em Ciências da Saúde da Universidade São Francisco, Bragança Paulista, São Paulo; ${ }^{3}$ Acadêmico do Curso de Medicina da Universidade São Francisco, Bragança Paulista, São Paulo; ${ }^{4}$ Professor Assistente Mestre da

Disciplina de Patologia do Curso de Medicina da Universidade São Francisco, Bragança Paulista, São Paulo;

5. Professor Adjunto Doutor do Programa de Pós-Graduação em Ciências da Saúde da Universidade São Francisco, Bragança Paulista, São Paulo.
\end{abstract}

MARQUES LHS; SILVA CMG; LAMEIRO TMM; ALMEIDA MG; CUNHA FL; PEREIRA JA; MARTINEZ CAR. Avaliação dos Níveis de Peroxidação Lipídica em Células da Mucosa Cólica após Aplicação de Enemas com Peróxido de Hidrogênio. Estudo Experimental em Ratos. Rev bras Coloproct, 2010;30(3): 272-280.

RESUMO: A aplicação de clisteres contendo peróxido de hidrogênio $\left(\mathrm{H}_{2} \mathrm{O}_{2}\right)$ determina o aparecimento de quadros graves de colite, algumas vezes de evolução fatal. É possível que a colite induzida por $\mathrm{H}_{2} \mathrm{O}_{2}$ possa ocorrer pela quebra da barreira funcional do epitélio cólico por estresse oxidativo. Objetivo: Avaliar os níveis de peroxidação lipídica em células da mucosa cólica após instilação de $\mathrm{H}_{2} \mathrm{O}_{2}$ no reto excluso de trânsito fecal. Método: Vinte seis ratos Wistar machos foram submetidos a colostomia proximal terminal no cólon descendente e fístula mucosa distal. Os animais foram randomizados em dois grupos segundo o sacrifício ter sido realizado duas ou quatro semanas após a derivação intestinal. Cada grupo experimental foi dividido e dois subgrupos segundo aplicação de clisteres, em dias alternados, contendo solução fisiológica a $0,9 \%$ ou $\mathrm{H}_{2} \mathrm{O}_{2}$ a $3 \%$. O diagnóstico de colite foi estabelecido por estudo histopatológico e os níveis de dano oxidativo tecidual pela dosagem de malondialdeído por espectrofotometria. Os resultados foram analisados com os testes de MannWhitney e Kruskal-Wallis, estabelecendo-se nível de significância de $5 \%(p<0,05)$. Resultados: Os níveis de malondialdeído nos irrigados com SF nos cólons com e sem trânsito fecal após duas e quatro semanas de irrigação foram de: $0,05 \pm 0,006$; $0,06 \pm 0,006$ e $0,05 \pm 0,03,0,08 \pm 0,02$, respectivamente. Os níveis de malondialdeído nos irrigados com $\mathrm{H}_{2} \mathrm{O}_{2}$, nos cólons com e sem trânsito, após duas e quatro semanas de irrigação foram de $0,070 \pm 0,006 ; 0,077 \pm 0,01$ e $0,052 \pm 0,01,0,08 \pm 0,04$, respectivamente. Após duas semanas os níveis de malondialdeído foram maiores nos animais irrigados com $\mathrm{H}_{2} \mathrm{O}_{2}$ em relação ao grupo controle ( $p=0,007$ e $p=0,01$, respectivamente). Após quatro semanas não houve diferenças significantes

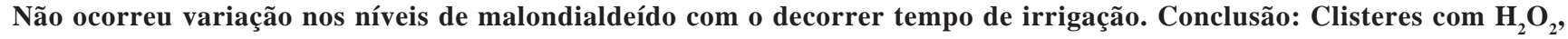
podem determinar o aparecimento de colite por ocasionarem estresse oxidativo nas células epiteliais da mucosa intestinal.

Descritores: Cólon; Colite, Peróxido de hidrogênio; Peroxidação de Lipídeos; Malondialdeído; Ácidos Graxos Voláteis; Ratos.

Trabalho realizado no Programa de Pós-graduação em Ciências da Saúde da Universidade São Francisco, Bragança Paulista, São Paulo.

Recebido em 08/07/2010

Aceito para publicação em 26/08/2010 
Avaliação dos Níveis de Peroxidação Lipídica em Células da Mucosa Cólica após Aplicação de Enemas com Peróxido de Hidrogênio. Estudo Experimental em Ratos Letícia Helena Souza Marques e Cols.

\section{INTRODUÇÃO}

Durante anos, a aplicação de clisteres contendo peróxido de hidrogênio $\left(\mathrm{H}_{2} \mathrm{O}_{2}\right)$ foi recomendada e utilizada para a eliminação de fezes impactadas no reto. ${ }^{(1)}$ Contudo, começaram a surgir casos graves de colite após aplicação de $\mathrm{H}_{2} \mathrm{O}_{2}$ no interior do reto, alguns deles com evolução fatal. ${ }^{(2,3,4)}$ A toxicidade do $\mathrm{H}_{2} \mathrm{O}_{2}$ à mucosa cólica pode ser melhor avaliada ao mostrar-se que mesmo pequenas quantidades da substância, aplicadas inadvertidamente durante a realização de procedimentos endoscópicos ou utilizadas para limpeza do equipamento, são capazes de deflagrar, em unidades de endoscopia, verdadeiras epidemias de colite. ${ }^{(1,5,6,7,8)}$ A colite induzida pelo $\mathrm{H}_{2} \mathrm{O}_{2}$ apresenta quadro clínico e histológico semelhantes aos encontrados na colite ulcerativa humana, sugerindo possíveis semelhanças nos mecanismos de lesão da mucosa cólica. ${ }^{(1)}$

A partir dessas evidências clínicas, pesquisas conseguiram reproduzir, experimentalmente em ratos, colites agudas e crônicas, de intensidade e gravidade variável, após aplicação retal de $\mathrm{H}_{2} \mathrm{O}_{2} \cdot{ }^{(4)}$ Dessa forma, a irrigação do intestino grosso com $\mathrm{H}_{2} \mathrm{O}_{2}$ tornouse um dos primeiros modelos experimentais de colite quimicamente induzida, que tentava reproduzir, em animais, a colite ulcerativa do homem. ${ }^{(1)} \mathrm{O}$ exame histopatológico da mucosa dos ratos que morriam em decorrência da colite induzida por $\mathrm{H}_{2} \mathrm{O}_{2}$ mostrava áreas de inflamação localizadas principalmente no cólon distal, ulcerações superficiais ou profundas da mucosa e infiltração de polimorfonucleares (PMN) nas criptas cólicas. Nos animais que sobreviviam à fase de indução da colite, a maioria das úlceras cicatrizava após 10 semanas, com exceção de algumas localizadas no cólon esquerdo e reto, logo acima do canal anal, mostrando que o modelo experimental proposto apresenta paralelismo ao observado na colite ulcerativa humana.

Entretanto, os mecanismos moleculares pelos quais o $\mathrm{H}_{2} \mathrm{O}_{2}$ ocasiona a lesão da mucosa intestinal ainda não foram totalmente esclarecidos. Estudos mostraram que a que exposição dos fosfolipídios que compõe às membranas celulares, a radicais livres de oxigênio (RLO) podem ser completamente destruídos por um fenômeno conhecido como peroxidação lipídica. É possível que na colite induzida por $\mathrm{H}_{2} \mathrm{O}_{2}$, a peroxidação lipídica danificando o mecanismo de barreira funcional exercido pelo epitélio possibilite infiltração bacteriana a partir da luz intestinal e a conseqüiente resposta inflamatória. Os PMN ativados liberando mediadores, citocinas e maior quantidade de RLO, com o objetivo de combater a infecção, propagariam ainda mais a destruição da mucosa intestinal. ${ }^{(1)}$ Entretanto, essa possibilidade ainda não foi estudada, nos segmentos do intestino grosso com menor concentração bacteriana. É possível que a lesão da mucosa intestinal possa ocorrer em virtude dos maiores níveis de estresse oxidativo desencadeado pela aplicação do $\mathrm{H}_{2} \mathrm{O}_{2}$ Assim sendo, o objetivo do presente estudo experimental foi avaliar os níveis de peroxidação lipídica na mucosa cólica de ratos após indução de colite por $\mathrm{H}_{2} \mathrm{O}_{2}$ em segmentos exclusos de trânsito fecal, relacionando-os ao tempo de intervenção com à substância.

\section{MÉTODO}

\section{Animais}

Foram utilizados 26 ratos Wistar machos, pesando entre 300 e $350 \mathrm{~g}$ provenientes do Biotério Central da Universidade São Francisco. Durante o período de vigilância epidemiológica (sete dias), os animais foram mantidos em gaiolas individuais, em ambiente climatizado, com controle de temperatura, luminosidade, umidade e ruídos. Na véspera da intervenção cirúrgica todos permaneceram em jejum durante $12 \mathrm{~h}$, exceto para água. Os ratos foram isolados em gaiolas individuais, identificadas com o número do animal, grupo e subgrupo experimental a que pertenciam. Esses mesmos dados foram tatuados com tinta da China na cauda. Após desmame todos os animais selecionados foram alimentados com dieta própria para roedores previamente esterilizada (Nuvilab CR $1{ }^{\circledR}$, Nuvital Nutrientes SA, São Paulo, Brasil) e pesados semanalmente. O estudo foi aprovado pelo Comitê de Ética no Uso de Animais em Pesquisa (CEUAP) da Universidade São Francisco e, todas as etapas experimentais, foram realizadas em conformidade com os princípios definidos pelo Colégio Brasileiro de Experimentação Animal (COBEA).

\section{Técnica cirúrgica}

O desvio do trânsito fecal foi realizado, em todos os animais, sob anestesia geral pela administração intramuscular de $0,1 \mathrm{ml} / 100 \mathrm{~g}$ de 1:1 (v/v) solução de quetamina $(50 \mathrm{mg} / \mathrm{ml})$ e xilazina $(20 \mathrm{mg} / \mathrm{ml})$ na pata traseira esquerda. Depois de anestesiados e fixos à mesa cirúrgica, em decúbito dorsal horizontal, realizouse tricotomia da região abdominal, da pelve até o re- 
Avaliação dos Níveis de Peroxidação Lipídica em Células da Mucosa Cólica após Aplicação de Enemas com Peróxido de Hidrogênio. Estudo Experimental em Ratos Letícia Helena Souza Marques e Cols.
Vol. 30 $\mathbf{N}^{\circ} 3$ bordo costal. A anti-sepsia da pele foi feita com polivinilpirolidona-iodo que, posteriormente, foi recoberta por campo fenestrado estéril. A cavidade abdominal foi aberta através de incisão longitudinal mediana com três centímetros de extensão. Durante o inventário da cavidade, identificou-se a placa de Peyer, estrutura linfóide situada na face anterior do cólon na transição entre o reto e o sigmóide. Com o auxílio de paquímetro, foi aferida a distância entre a placa de Peyer e o local escolhido para a secção do cólon esquerdo, quatro centímetros acima da extremidade superior da placa. Após ligadura dos vasos da arcada marginal seccionou-se o cólon no ponto escolhido exteriorizando-se o segmento proximal, como colostomia terminal, através de incisão circular, com três milímetros de diâmetro, realizada no hipocôndrio esquerdo. Fixou-se a colostomia à pele com pontos separados de fio absorvível monofilamentar 4-0 (Monocryl $^{\circledR}$, Ethicon, Inc. Somerville, NJ, USA) nos quatro pontos cardinais, e depois entre eles, amarrando com três nós.

Terminada a confecção da colostomia proximal, o segmento caudal do intestino grosso foi cateterizado com sonda de polivinil medindo $12 \mathrm{~F}$, e irrigado com 40 $\mathrm{ml}$ de solução fisiológica $0,9 \%(\mathrm{SF})$ a $37^{\circ} \mathrm{C}$, até que o efluente drenado pelo ânus não mais apresentasse resíduos fecais. Concluída a irrigação, o cateter foi removido e o cólon distal exteriorizado como colostomia (fístula mucosa distal) na face lateral inferior esquerda da parede abdominal. O estoma distal foi fixado com a mesma técnica utilizada no proximal. A síntese da parede abdominal foi realizada em dois planos de sutura: peritônio e aponeurose com pontos contínuos de fio de ácido poliglicólico 4-0 (Vicryl ${ }^{\circledR}$, Ethicon, Inc. Somerville, NJ, USA) e a pele com pontos separados de nylon 4-0 (Mononylon ${ }^{\circledR}$ ).

\section{Grupos experimentais}

Os 26 animais submetidos ao desvio do trânsito fecal foram randomizados em dois grupos experimentais composto de 13 animais, segundo o sacrifício ter sido realizado duas ou quatro semanas após a derivação do trânsito fecal. Cada grupo experimental foi dividido em dois subgrupos de acordo com a solução de intervenção aplicada no reto. No primeiro subgrupo, aplicou-se enemas retais, em dias alternados, contendo $20 \mathrm{ml}$ de $\mathrm{SF} 0,9 \%$ à $37^{\circ} \mathrm{C}$ (grupo controle; $\mathrm{n}=4$ ). No segundo subgrupo os clisteres continham $20 \mathrm{ml} \mathrm{de} \mathrm{H}_{2} \mathrm{O}_{2}$ a $3 \%$ (grupo experimental; $n=9$ ).

\section{Coleta das amostras}

Duas ou quatro semanas após a intervenção com as substâncias propostas os animais foram novamente anestesiados, com a mesma técnica anteriormente, a cavidade abdominal foi reaberta, removendose dois fragmentos com quatro centímetros obtidos dos segmentos cólicos submetidos ou não a irrigação com as soluções de intervenção. Os espécimes removidos foram abertos longitudinalmente pela borda antimesentérica e subdivididos em dois fragmentos, com dois centímetros de comprimento de extensão, destinados ao estudos histológico e a avaliação dos níveis de lipoperoxidação pela quantificação dos níveis teciduais de malondialdeído (MDA). Nos fragmentos encaminhados para avaliação dos níveis de MDA a mucosa foi separada das demais camadas da parede cólica por dissecação com auxílio de lupa.

\section{Análise histológica}

Os fragmentos destinados a análise histológica foram imediatamente imersos em paraformaldeído a $4 \%$ em PBS, por $24 \mathrm{~h}$ e após, desidratados em concentrações crescentes de etanol. Terminada a desidratação, foram inclusos em blocos de parafina e, a partir destes realizou-se cortes histológicos com 5 ìm de espessura, posteriormente montados sobre uma lâmina de vidro. Depois de montados os cortes foram re-hidratados e corados com hematoxilina-eosina (HE) para avaliação da presença de colite. As lâminas foram analisadas por patologista experiente no diagnóstico de doenças inflamatórias colorretais, que desconhecia os objetivos do estudo. Para o diagnóstico da colite considerou-se dois parâmetros principais: a infiltração de PMN e a presença de erosões epiteliais ou úlceras.

\section{(MDA)}

\section{Determinação dos níveis de malondialdeído}

A medida dos níveis de peroxidação lipídica foi avaliada pela dosagem das substâncias reativas ao ácido tiobarbitúrico (TBARS), tais como o MDA segundo metodologia anteriormente proposta. ${ }^{9}$ O MDA é um dos produtos secundários da liporeroxidação lipídica, sendo considerado candidato potencial como um biomarcador geral de estresse oxidativo tecidual. Para a quantificação dos níveis tissulares de MDA, resumidamente, $1 \mathrm{~g}$ de cada fragmento cólico foi colocada em $5 \mathrm{~mL}$ de tampão fosfato e homogeneizada em vórtex e no ultra-sonicador por 30 segundos, repetindo-se o pro- 
cesso três vezes, alternadamente. A seguir, $250 \mu \mathrm{L}$ do sobrenadante, obtido no processo de homogeneização, foram transferidos para tubo plástico contendo $25 \mu \mathrm{L}$ de BHT 4\% metanólico e, novamente, homogeneizados no vórtex. A seguir adicionou-se $1 \mathrm{~mL}$ de ácido tricloroacético a $12 \%, 1 \mathrm{~mL}$ de ácido tiobarbitúrico a $0,73 \%$ e $750 \mu \mathrm{L}$ de tampão tris/ $\mathrm{HCl}$ incubando-se em banho maria, a $100^{\circ} \mathrm{C}$, por 60 minutos. Terminada esta etapa os tubos foram imediatamente acondicionados em recipiente contendo gelo para bloquear a reação. A seguir acrescentou-se $1,5 \mathrm{~mL}$ de n-butanol homogeneizando-se, no vórtex, por mais 30 segundos. A seguir, os tubos foram centrifugados por 10 minutos a $5.000 \mathrm{rpm}$. O sobrenadante foi removido, sendo realizada a leitura da coloração em espectrofotômetro Lambda 45UV/VIS (Perkin-Elmer Inc., Massachussetts, USA) em absorbância de 532nm.

\section{Análise estatística}

Os valores teciduais de MDA nos segmentos irrigados e não irrigados com as soluções de intervenção foram expressos pelo valor médio com o respectivo desvio-padrão. Os resultados encontrados nos segmentos expostos e não expostos a solução fisiológica e ao $\mathrm{H}_{2} \mathrm{O}_{2}$ foram comparados pelo teste de MannWhitney. A variação nos níveis de teciduais de MDA nos diferentes tempos de irrigação foi avaliada pelo teste de Kruskal-Wallis. Na análise estatística dos resultados encontrados adotou-se nível de significância de 5\% ( $\mathrm{p}<0,05)$, utilizando-se o programa SPSS ${ }^{\circledR}$ (SPSS Inc., Chicago, USA) versão 13.0 para Windows.

\section{RESULTADOS}

A figura 1 mostra a superfície mucosa de segmentos cólicos submetidos à irrigação do cólon distal com SF $0,9 \%$ (A) ou com $\mathrm{H}_{2} \mathrm{O}_{2}$ a $3 \%$ (B) por duas semanas. Nos segmentos expostos ao $\mathrm{H}_{2} \mathrm{O}_{2}$ a mucosa encontra-se hiperemiada, congesta com a formação de úlceras superficiais com sangramento local.

A figura 2A mostra cortes histológicos longitudinais da parede cólica de segmento não irrigado enquanto a figura 2B mostra segmento cólico irrigado com $\mathrm{H}_{2} \mathrm{O}_{2}$ a $3 \%$ por duas semanas. Nos segmentos expostos ao $\mathrm{H}_{2} \mathrm{O}_{2}$ as criptas cólicas encontram-se destruídas, com formação de úlceras superficiais, congestão vascular da submucosa e ruptura da camada muscular da mucosa.
A figura 3 mostra os níveis de MDA, nos segmentos com e sem trânsito, comparando animais submetidos à intervenção com $\mathrm{SF}$ ou $\mathrm{H}_{2} \mathrm{O}_{2}$ por duas semanas. Os resultados mostram que tanto nos segmentos irrigados quanto nos segmentos não irrigados os animais submetidos à intervenção com $\mathrm{H}_{2} \mathrm{O}_{2}$ apresentam níveis de MDA maiores dos que os submetidos à intervenção com SF $0,9 \%$.

A figura 4 mostra os níveis de MDA, nos segmentos com e sem trânsito, comparando animais submetidos à intervenção com $\mathrm{SF}$ ou $\mathrm{H}_{2} \mathrm{O}_{2}$ por quatro semanas. Os resultados mostram que tanto nos segmentos irrigados quanto nos não irrigados os níveis de MDA foram semelhantes. Os níveis de MDA nos segmentos irrigados tanto com SF quanto com $\mathrm{H}_{2} \mathrm{O}_{2}$ fecal foram maiores que os dos segmentos não irrigados.

A figura 5 mostra a variação nos níveis de MDA nos segmentos submetidos à irrigação ou não com $\mathrm{H}_{2} \mathrm{O}_{2}$ comparando animais irrigados por duas ou quatro semanas. Verifica-se que os níveis de MDA não aumentaram com o decorrer do tempo de irrigação.

\section{DISCUSSÃO}

Nos últimos anos, importância cada vez maior vem sendo dada ao papel desempenhado pelos RLO, na iniciação e progressão da agressão à mucosa cólica nas doenças inflamatórias intestinais..$^{(1,10,11,12.13)}$ Estudos experimentais confirmaram o papel representado pelos RLO no desenvolvimento da colite quimicamente induzida por ácido acético, TNBS e DSS. ${ }^{(14,15,16,17)}$

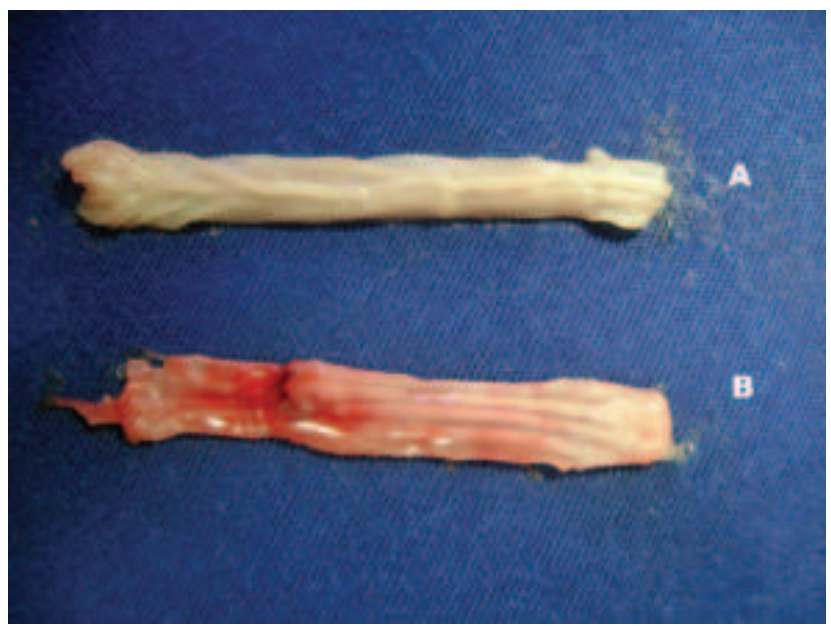

Figura 1 - A) Segmento cólico de animal irrigado com $\mathrm{SF} 0,9 \%$ por duas semanas. B) Segmento cólico irrigado com $\mathrm{H}_{2} \mathrm{O}_{2}$ por duas semanas. 


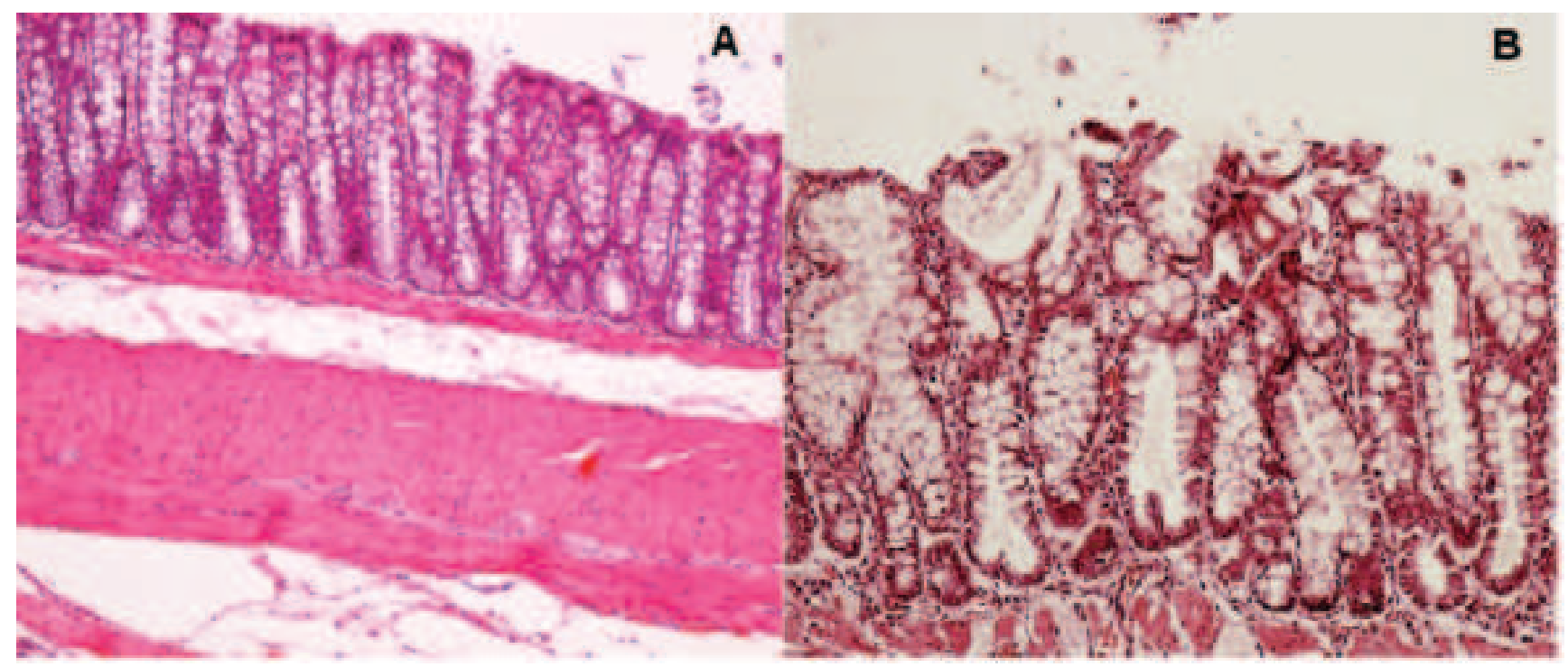

Figura 2 -A) Segmento do cólon provido de trânsito dos animais irrigados com solução fisiológica 0,9\% por duas semanas. B) Segmento cólico desprovido de trânsito dos animais irrigados com $\mathrm{H}_{2} \mathrm{O}_{2}$ por duas semanas.

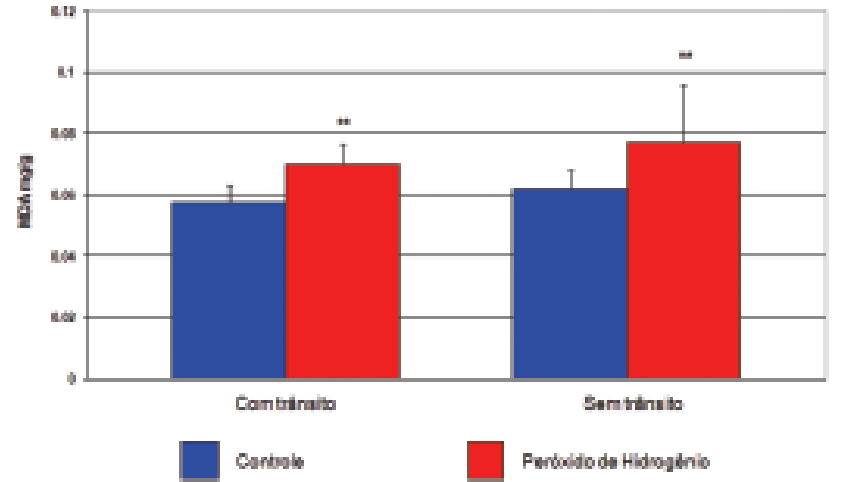

Figura 3 - Níveis teciduais de MDA comparando segmentos submetidos ou não a irrigação com enemas de $\mathrm{H}_{2} \mathrm{O}_{2}$ por duas semanas ** significante; $p<0,01$. Teste de Mann-Whitney.

Radicais livres são átomos ou moléculas que possuem número ímpar de elétrons na sua última camada eletrônica, tornando a molécula extremamente reativa. ${ }^{(18)}$ A denominação RLO é adotada porque a maioria dos radicais livres é gerada a partir do metabolismo celular do oxigênio.

Os RLO são constantemente formados durante a respiração de todas as células vivas. A maior parte dos RLO são formados durante a fosforilação oxidativa no interior das mitocôndrias. ${ }^{(1)}$ Quando são produzidos em excesso tornam-se nocivos às células, danificando proteínas, membranas, organelas e bases nitrogenadas do DNA possibilitando o surgimento de mutações. ${ }^{(23,1920,21)}$ Como mecanismos de defesa as células

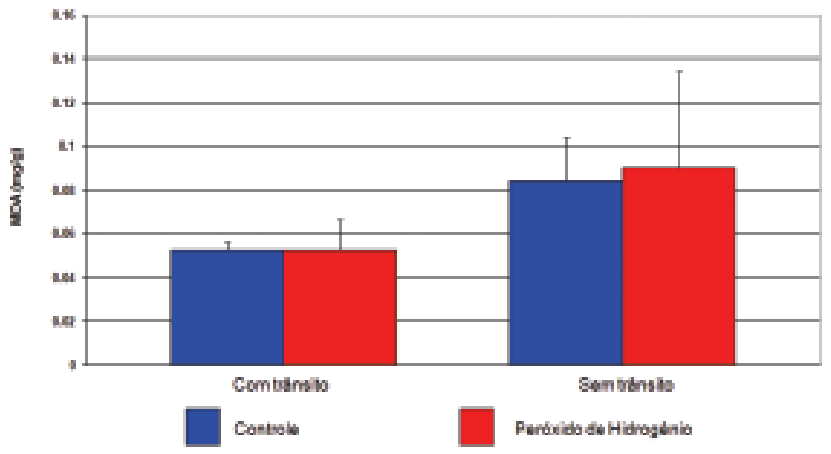

Figura 4 - Níveis teciduais de MDA comparando segmentos submetidos ou não a irrigação com enemas de $\mathrm{H}_{2} \mathrm{O}_{2}$ por quatro semanas.

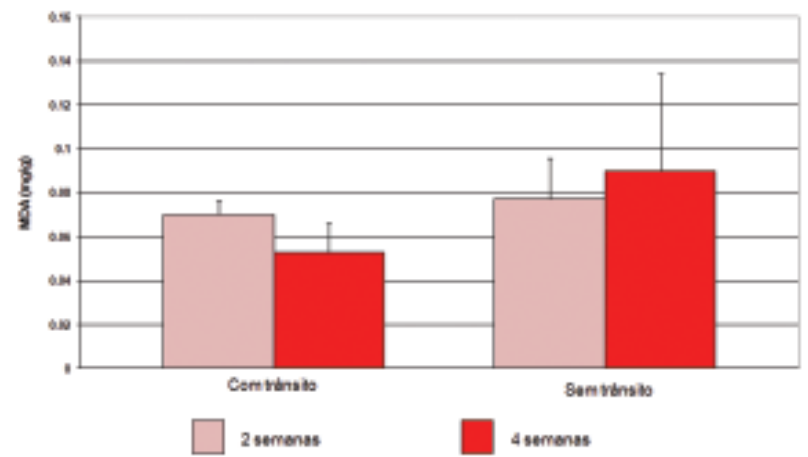

Figura 5 - Variação nos níveis teciduais de MDA nos segmentos submetidos ou não a irrigação com enemas de $\mathrm{H}_{2} \mathrm{O}_{2}$ após duas ou quatro semanas de experimento. 
possuem sistemas antioxidantes, que matem o equilíbrio entre produção de RLO e sua neutralização. .1,21) $^{(1,1)}$ Todavia, quando existe desequilíbrio entre produção e neutralização dos RLO, surge fenômeno conhecido como estresse oxidativo. ${ }^{(20,21)}$ Estudos já demonstraram os sistemas antioxidantes existentes na mucosa cólica são deficientes, quando comparados aos de outros órgãos e tecidos, tornando-a mais vulnerável ao estresse oxidativo. Na mucosa do intestino grosso o estresse oxidativo ocorre de forma mais freqüente e intensa quando comparado a outros órgãos, pela constante exposição à substâncias oxidantes formadas no interior do lume intestinal. ${ }^{(17)}$

Os mecanismos moleculares pelos quais o $\mathrm{H}_{2} \mathrm{O}_{2}$ danifica a mucosa cólica ainda não se encontram completamente esclarecidos. $\mathrm{O}_{2} \mathrm{O}_{2}$ é um produto intermediário formado durante a redução do oxigênio molecular em água. ${ }^{(22)}$ Nas células epiteliais da mucosa cólica $90 \%$ de todo o $\mathrm{H}_{2} \mathrm{O}_{2}$ celularé produzido, a partir da metabolização dos ácidos graxos de cadeia curta (AGCC) formados a partir da fermentação de fibras alimentares ingeridas na dieta. Esse processo é responsável pela síntese do ATP, principal fonte de energia para os processos metabólicos celulares que requerem energia. ${ }^{(23,24)} \mathrm{O} \mathrm{H}_{2} \mathrm{O}_{2}$ apesar de não ser considerado um RLO propriamente dito, por não possuir um elétron desemparelhado em sua última camada eletrônica, pode danificar tecidos pela sua alta capacidade de difusão através das membranas celulares. $\mathrm{O}_{2} \mathrm{O}_{2}$ também danifica as membranas celulares por apresentar intensa reatividade com os fosfolipídios componentes das membranas, proteínas citoplasmáticas e bases nitrogenadas. Quando existe aumento da produção de $\mathrm{H}_{2} \mathrm{O}_{2}$ pelos tecidos cólicos, través da reação de Haber-Weiss com o íon ferro existente na luz intestinal e formado a partir da decomposição da hemoglobina, ocorre à formação do radical $\mathrm{OH} \cdot$ considerado o mais danoso de todos os RLO conhecidos. ${ }^{(1)} \mathrm{O}$ radical $\mathrm{OH}$ possui alta afinidade pelos fosfolipídios constituintes das membranas celulares, determinando sua oxidação. ${ }^{(25,26,27,28,29)}$ Por seus efeitos bactericidas, também são produzidos em grande quantidade por PMN da parede cólica que têm a função de combater uma eventual infiltração bacteriana. Já se propôs que lesão tecidual da mucosa cólica, encontrada na colite ulcerativa decorre da maior capacidade dos PMN em formar e liberar grandes quantidades de RLO. ${ }^{(30)}$ Outras pesquisas atribuem a maior formação de RLO às próprias células epiteliais com modificações do seu metabolismo celular. ${ }^{(1)}$ Após a lesão da barreira epitelial existiria infiltração bacteriana e migração de PMN para o local. Apesar das controvérsias, quando se demonstrou que o $\mathrm{H}_{2} \mathrm{O}_{2}$ é capaz de induzir dano as células da mucosa cólica, é razoável supor que a aplicação de clisteres com $\mathrm{H}_{2} \mathrm{O}_{2}$ possa ocasionar dano tecidual pelo aumento da exposição e menor capacidade de neutralização num local onde os sistemas antioxidantes são deficientes. ${ }^{(17)}$

Entretanto, a manutenção do trânsito fecal não permite verificar se $\mathrm{o}_{2} \mathrm{O}_{2}$ pode induzir colite apenas por seus efeitos diretos sobre o epitélio ou também por RLO produzidos por PMN ativados para combater a infiltração bacteriana. Assim sendo, para avaliar com maior fidedignidade o papel do $\mathrm{H}_{2} \mathrm{O}_{2}$ na indução da colite seria interessante utilizar modelo experimental de colite onde existisse o menor conteúdo de fezes possível. Foi por essa razão que no presente estudo, optou-se pela exclusão de trânsito fecal no segmento cólico exposto à intervenção com $\mathrm{H}_{2} \mathrm{O}_{2}$. Com o objetivo de reduzir ao máximo o conteúdo fecal durante a derivação de trânsito irrigou-se o cólon excluso com SF até que o efluente drenado não mais apresentasse saída de resíduos fecais. Esse objetivo pode ser alcançado uma vez que durante o sacrifício em nenhum animal encontrou-se resquícios fecais assegurando a eficácia da limpeza mecânica.

Todavia, estudos mostraram que a simples supressão do fornecimento dos AGCC, às células da mucosa cólica, como ocorre na exclusão do trânsito fecal, é capaz de aumentar a produção de RLO ocasionando o aparecimento de colite. ${ }^{(10,11)}$ Demonstraram ainda, que a produção aumentada RLO encontra-se relacionada as alterações histológicas e bioquímicas que caracterizam a colite. Esses resultados confirmam a susceptibilidade da mucosa cólica aos efeitos lesivos dos RLO. Com o objetivo de quantificar os níveis de estresse oxidativo tecidual ocasionado somente pela derivação fecal é que utilizamos um grupo controle irrigado apenas com SF. Dessa forma, os eventuais níveis de MDA encontrados nos segmentos cólicos exclusos irrigados com SF traduziriam os níveis de dano oxidativo provocado, apenas, pela deficiência do suprimento energético.

Apesar dos níveis de estresse oxidativo, poder ser quantificado com diferentes métodos, todos confirmam a relação direta existente entre aumento na formação de RLO e dano à mucosa cólica. Dos vários 
métodos empregados para mensuração a dosagem do MDA é um dos mais freqüentemente utilizados. ${ }^{(31,32)} \mathrm{O}$ MDA é um produto secundário da peroxidação lipídica, sendo derivado da â-ruptura de ácidos graxos poliinsaturados, tais como o ácido linoléico, araquidônico e docosaexaenóico. A quantificação tecidual dos níveis de MDA é técnica de simples execução que permite avaliar a intensidade da oxidação de fosfolipídios celulares.

Os resultados encontrados no presente estudo confirmaram a validade do emprego do MDA na avaliação da lipoperoxidação, ao demonstrarem que ocorre estresse oxidativo tanto nos segmentos irrigados quanto nos não irrigados com qualquer das soluções de intervenção propostas, independente do tempo de aplicação dos clisteres. Ao compararem-se segmentos com ou sem trânsito fecal irrigados com SF verificou-se que os níveis de MDA encontravam-se mais elevados nos segmentos sem trânsito, sobretudo após quatro semanas. Estes dados confirmam os resultados de estudos anteriores, em modelos experimentais de CE, que mesmo sem realizarem clisteres com substâncias oxidantes e adotando outros métodos para quantificar os níveis de estresse oxidativo, também encontraram valores maiores níveis no cólon desprovido de trânsito fecal. ${ }^{(33,3434}$. Os níveis de MDA mais elevados confirmam as suspeitas que a diminuição acentuada do suprimento de AGCC às células epiteliais cólicas, modificando o metabolismo celular, é capaz de aumentar à produção de RLO e ocasionar dano oxidativo ao epitélio mucoso. Os níveis de MDA mais elevados no cólon sem trânsito após quatro semanas também vem de encontro aos resultados encontrados em estudos anteriores mostrando com o progredir do tempo de exclusão fecal mantém a mucosa cólica a um constante dano oxidativo. $^{(28,29,33,34)}$

Os níveis de MDA no cólon provido de trânsito nos animais submetidos à irrigação com $\mathrm{H}_{2} \mathrm{O}_{2}$ por duas semanas foram significativamente maiores quando comparados aos dos animais irrigados com SF. Os maiores níveis nos irrigados com $\mathrm{H}_{2} \mathrm{O}_{2}$ talvez possam ser explicados por um efeito sistêmico. Os RLO poderiam estar sendo absorvido pelo cólon sem trânsito e danificando às membranas da mucosa dos segmentos com trânsito preservado. No cólon sem trânsito irrigado com $\mathrm{H}_{2} \mathrm{O}_{2}$, os níveis mais elevados de MDA provavelmente decorram da ação direta da substância sobre o epitélio mucoso colorretal somado a um valor basal ocasionado pela exclusão fecal. O desvio de trânsito fecal realizado nesses segmentos, reduzindo a presença de bactérias e, conseqüentemente a infiltração de PMN sugere que os maiores níveis de estresse oxidativo relacionam-se a ação direta do $\mathrm{H}_{2} \mathrm{O}_{2}$ e da deficiência energética proporcionada pela exclusão fecal. Essas possibilidades ficam mais evidentes ao analisarem-se os aspectos macroscópicos e microscópicos, comparando segmentos irrigados com $\mathrm{SF}$ ou $\mathrm{H}_{2} \mathrm{O}_{2}$. Em ambos os segmentos o exame histopatológico mostrava, achados consistentes com o diagnóstico de colite. Microscopicamente, a quantidade de infiltrado de PMN foi semelhante nos segmentos sem trânsito de animais irrigados com ambas as soluções. Todavia, a destruição da superfície epitelial foi mais evidente nos animais submetidos à intervenção com $\mathrm{H}_{2} \mathrm{O}_{2}$, confirmando os efeitos tóxicos da substância. Estudos anteriores também confirmaram que no cólon sem trânsito, à medida que progride o tempo de exclusão o estresse oxidativo encontra-se inversamente relacionado à infiltração neutrofílica avaliada pelos níveis teciduais de mieloperoxidase. ${ }^{(28)}$

Nos animais submetidos à intervenção com $\mathrm{H}_{2} \mathrm{O}_{2}$ ou SF por quatro semanas os níveis de MDA nos segmentos não irrigados, de modo diferente ao que ocorria naqueles irrigados por duas semanas, não diferiam. É provável, que a piora da lesão ao epitélio mucoso do cólon irrigado, destruindo as criptas cólicas, reduziriam a capacidade de absorção de RLO diminuindo o efeito sistêmico sobre o cólon não irrigado. Os níveis de MDA nos segmentos irrigados com SF ou $\mathrm{H}_{2} \mathrm{O}_{2}$ também não mostravam diferenças significantes. É possível, que a exclusão de trânsito fecal mais prolongada aumentando dano tecidual torne a mucosa cólica menos susceptível a um estresse adicional provocado pela exposição ao $\mathrm{H}_{2} \mathrm{O}_{2}$.

Não houve variação nos níveis de MDA no cólon com trânsito nos animais submetidos à intervenção com $\mathrm{H}_{2} \mathrm{O}_{2}$ por duas ou quatro semanas. Do mesmo modo, também não ocorreu variação nos níveis de MDA comparando segmentos cólicos irrigados com $\mathrm{H}_{2} \mathrm{O}_{2}$ por duas ou quatro semanas. Esses resultados sugerem que a exclusão do trânsito fecal, modificando o metabolismo epitelial das células da mucosa cólica, já é capaz de provocar peroxidação lipídica tecidual tão intensa que não variam mesmo após uma maior exposição à RLO.

Os resultados encontrados no presente estudo confirmam que a exclusão fecal ocasiona estresse oxidativo tecidual nos segmentos sem de trânsito fecal, 
Rev bras Coloproct Julho/Setembro, 2010
Avaliação dos Níveis de Peroxidação Lipídica em Células da Mucosa Cólica após Aplicação de Enemas com Peróxido de Hidrogênio. Estudo Experimental em Ratos Letícia Helena Souza Marques e Cols.
Vol. 30 $\mathbf{N}^{\circ} 3$ como encontrado em estudos anteriores. ${ }^{(33,34)}$ Mostraram que a aplicação de clisteres com $\mathrm{H}_{2} \mathrm{O}_{2}$ ocasiona peroxidação lipídica que relaciona-se às alterações histológicas que permitem o diagnóstico de colite. Su- gerem ainda, que a colite induzida por $\mathrm{H}_{2} \mathrm{O}_{2}$ possa ser um modelo de colite experimental interessante para avaliação do potencial antioxidante de várias substâncias empregadas no tratamento da $\mathrm{CE}$.

ABSTRACT: The use of rectal enemas with hydrogen peroxide $\left(\mathrm{H}_{2} \mathrm{O}_{2}\right)$ determines the onset of severe colitis, sometimes with fatal evolution. It is possible that $\mathrm{H}_{2} \mathrm{O}_{2}$-induced colitis can occur by damage to the functional epithelial barrier of the colon by oxidative stress. Objective: The aim of present study was evaluate the levels of lipid peroxidation in cells of the colonic mucosa after instillation of $\mathrm{H}_{2} \mathrm{O}_{2}$ into the rectum excluded from fecal transit. Method: Twenty six male Wistar rats were undergone to proximal terminal colostomy in the descending colon and distal mucous fistula. The animals were randomized in two experimental groups according to the sacrifice was made two or four weeks after diversion of the fecal stream. Each experimental group was divided into two subgroups second application of enemas containing saline solution $0.9 \%$ or $3 \% \mathrm{H}_{2} \mathrm{O}_{2}$ on alternate days. The diagnosis of colitis was established by histopathology study and the oxidative damage by tissue levels of malondialdehyde quantified by spectrophotometry. The results were analyzed with the Mann-Whitney and Kruskal-Wallis test, adopting a significance level of $5 \%(\mathrm{p}<0.05)$. Results: The levels of malondialdehyde in colon segments irrigated with saline, with and without fecal stream after two and four weeks of irrigation were: $0.05 \pm 0.006,0.06 \pm 0.006$ and $0.05 \pm 0.03,0.08 \pm 0.02$, respectively. The levels of malondialdehyde in colon segments irrigated with $\mathrm{H}_{2} \mathrm{O}_{2}$, in the colon with and without fecal stream, after two and four weeks of irrigation were $0.070 \pm 0.006,0.077$ and $0.052 \pm 0.01 \pm 0.01,0.08 \pm 0.04$, respectively . After two weeks the levels of malondialdehyde were higher on animals irrigated with $\mathrm{H}_{2} \mathrm{O}_{2}$ than control group $(p=0.007$ and $p=0.01$, respectively). After four weeks there were no significant differences in malondialdehyde levels related with the time of irrigation. Conclusion: Rectal enemas with $\mathrm{H}_{2} \mathrm{O}_{2}$, may determine the onset of colitis by oxidative stress on epithelial cells of intestinal mucosa.

Key words: Colon; Colitis; Hydrogen Peroxide; Lipid Peroxidation; Malondialdehyde; Fatty acids, Volatile; Rats.

\section{REFERÊNCIAS}

1. Pravda J. Radical induction theory of ulcerative colitis. World J Gastroenterol. 2005;11;2371-84.

2. Benson K, Bargen J. Fecal impaction. Am J M Sc.1939;198: 541-5.

3. Pumphery RE. Hydrogen peroxide proctitis. Am J Surg.1951;81:60-2.

4. Sheenan J, Brynjolfsson G. Ulcerative colitis following hydrogen peroxide enema. Lab Invest.1960;9:150-67.

5. Meyer CT, Brand M, DeLuca VA, Spiro HM. Hydrogen peroxide colitis: a report of three patients. J Clin Gastroenterol. 1981; 3:31-35

6. Bilotta J, Waye JD. Hydrogen peroxide enteritis: the "snow white" sign. Gastrointest Endosc. 1989; 35: 428-30.

7. Almalouf P, Shehab TM, Daniel AM, Robinson EA, Barnett JL. Therapeutic hydrogen peroxide enema causing severe acute colitis. Int J Colorectal Dis. 2008;23:1139-40.

8. Cammarota G, Cesaro P, Cazzato A, Fedeli P, Riccioni ME, Sparano L, Vitale G, Costamagna G, Gasbarrini G, Larocca LM. Hydrogen peroxide-related colitis (previously known as "pseudolipomatosis"): a series of cases occurring in an epidemic pattern. Endoscopy. 2007;39:916-9.

9. Ohkawa H, Ohishi Í, Yagi Ê. Assay for lipid peroxides in animal tissues by thiobarbituric acid reaction; Anal. Biochem. 1979;95:351-8.
10. Kruidenier L, Verspaget HW. Review article: oxidative stress as a pathogenic factor in inflammatory bowel disease: radicals or ridiculous. Aliment Pharmacol Ther. 2002;16:1997-2015.

11. Dryden GW Jr, Deaciuc I, Arteel G, McClain CJ. Clinical implications of oxidative stress and antioxidant therapy. Curr Gastroenterol Rep. 2005;7:308-16.

12. Rezaie A, Parker RD, Abdollahi M. Oxidative stress and pathogenesis of inflammatory bowel disease an epiphenomenon or the cause. Dig Dis Sci. 2007;52:2015-21.

13. Strus M, Gosiewski T, Fyderek K, Wedrychowicz A, Kowalska-Duplaga K, Kochan P, Adamski P, Heczko PB. A role of hydrogen peroxide producing commensal bacteria present in colon of adolescents with inflammatory bowel disease in perpetuation of the inflammatory process. J Physiol Pharmacol. 2009;60(Suppl 6):49-54.

14. Grisham MB, Volkmer C, Tso P, Yamada T. Metabolism of trinitrobenzene sulfonic acid by the rat colon produces reactive oxygen species. Gastroenterology. 1991;101:540-7.

15. Chamulitrat W, Spitzer JJ. Generation of nitro and superoxide radicals anions from 2,4,6-trinitrobenzenesulfonic acid by rat gastrointestinal cells. Biochim Biophys Acta. 1997;1336:7382.

16. Damiani CR, Benetton CA, Stoffel C, Bardini KC, Cardoso VH, Di Giunta G, Pinho RA, Dal-Pizzol F, Streck EL. Oxidative stress and metabolism in animal model of colitis 
induced by dextran sulfate sodium. J Gastroenterol Hepatol. 2007;22:1846-51.

17. Fillmann H, Kretzmann NA, San-Miguel B, Llesuy S, Marroni N, González-Gallego J, Tuñón MJ. Glutamine inhibits overexpression of pro-inflammatory genes and down-regulates the nuclear factor kappaB pathway in an experimental model of colitis in the rat. Toxicology. 2007;236:217-26.

18 Gutteridge JM, Halliwell B. Free radicals and antioxidants in the year 2000. A historical look to the future. Ann N Y Acad Sci. 2000;899:136-47.

19. Ribeiro ML, Priolli DG, Miranda DD, Arçari DP, Pedrazzoli $\mathrm{J}$ Jr, Martinez CA. Analysis of oxidative DNA damage in patients with colorectal cancer.Clin Colorectal Cancer. 2008;7:267-72.

20. Cadenas E, Davies KJ. Mitochondrial free radical generation, oxidative stress, and aging. Free Rad Biol Med. 2000;29:22230 .

21. McCord JM. The evolution of free radicals and oxidative stress. Am J Med. 2000;108:652-9.

22. Chance B, Sies, H, Boveris A. Hydroperoxide metabolism in mammalian organs. Physiol Rev.1979;59:527-605.

23. Thannickal VJ, Fanburg BL. Reactive oxygen species in cell signaling, Am J Physiol Lung Cell Mol Physiol. 2000;279:100528.

24. Eaton JW, Qian M. Molecular basis of cellular iron toxicity. Free Radic Biol Med. 2002;32:833-40.

25. Cadenas E, Davies KJ. Mitochondrial free radical generation, oxidative stress, and aging. Free Rad Biol Med. 2000;29:22230 .

26. Gutteridge JM, Halliwell B. Free radicals and antioxidants in the year 2000. A historical look to the future. Ann N Y Acad Sci. 2000;899:136-47.

27. McCord JM. The evolution of free radicals and oxidative stress. Am J Med. 2000;108:652-9.
28. Longatti TS, Acedo SC, de Oliveira CC,et al. Inflammatory alterations in excluded colon in rats - a comparison with chemically-induced colitis. Scand J Gastroenterol. 2010;45:315-24.

29. Martinez CA, Bartocci PC, do Carmo CV, Pereira JA, Miranda DD, Ribeiro ML, The effects of oxidative DNA damage and mutations in the 553 protein on cells of the colonic mucosa with and without the fecal stream: an experimental study in rats. Scand J Gastroenterol. 2010;45:714-24.

30. Liu Q, Shimoyama T, Suzuki K, Umeda T, Nakaji S, Sugawara $\mathrm{K}$. Effect of sodium butyrate on reactive oxygen species generation by human neutrophils. Scand J Gastroenterol. 2001; 36:744-50.

31. Lee IA, Bae EA, Hyun YJ, Kin DH. Dextran sulfate sodium and 2,4,6-trinitrobenzene sulfonic acid induce lipid peroxidation by the proliferation of intestinal gram-negative bacteria in mice. J Inflamm (London). 2010; 7:7.

32. Arafa HM, Hemeida RA, El-Bahrawy AI, Hamada FM. Prophylactic role of curcumin in dextran sulfate sodium (DSS)induced ulcerative colitis murine model. Food Chem Toxicol. 2009;47:1311-7.

33. Martinez CAR, Priolli DG, Ribeiro ML, Gambero A, Silva CMG, Pereira JA, Nadal SR. The importance of oxygen free radicals in the etiopathogenesis of diversion colitis in rats. Acta Cir Bras. 2010. No prelo.

34. Martinez CAR. O estresse oxidativo na etiopatogenia da colite de exclusão. Estudo experimental em ratos. Tese (Doutorado em Cirurgia Geral). São Paulo (SP): Faculdade de Ciências Médicas da Santa Casa de São Paulo, 2009.

\section{Endereço para correspondência:}

\section{CARLOS AUGUSTO REAL MARTINEZ}

Rua Rui Barbosa, 255 apto. 32

Santo André (SP) - 09190-370

e-mail: caomartinez@uol.com.br 